\title{
26303 - STUDENT OPINIONS OF PART TASK AND HIGH-FIDELITY SIMULATION EDUCATION
}

\section{Pamela Morgan MD CCFP FRCPC, DoreenCleave-Hogg, PhD; Susan Desousa, BSc, RRT; Michele Haley, Sunnybrook And Women's College Health Sciences Centre, Toronto, ON, Canada}

INTRODUCTION: There is evidence in the medical education literature that students are not being exposed to adequate procedural skills training during the undergraduate medical years. In particular, during an anesthesia rotation, the ability to acquire skills such as patient monitoring, intravenous insertion, bag/mask ventilation, laryngeal mask insertion and endotracheal intubation have become problematic for many reasons. Parttask and high fidelity simulation offer students the chance to practice skills in a safe environment.

METHODS: Educational sessions were organized every 2 weeks with 10-12 students participating per session. After REB approval, students were given an orientation to the Simulation Centre and to each of the 5 stations which included; 1-Patient Monitoring (Datex Light portable monitor); 2-Intravenous insertion (2 Laerdal IV training arms); 3Bag-mask ventilation and endotracheal intubation (Laerdal Airway Management Trainer); 4- Laryngeal mask insertion (METI AirSim); and 5-High-fidelity simulation (HFS) scenario focusing on induction and maintenance of general anesthesia and management of a clinical scenario (Eagle MedSim high-fidelity patient simulator). The students were divided into groups of 2-3 students and given 45 minutes at each station. Learning objectives and tasks that the students were expected to complete were provided at each station. The learning objectives were developed from the undergraduate curriculum at the University of Toronto. Each station also contained relevant reading material to guide the students through the objectives and tasks. Three facilitators and a simulator operator were present to help guide the students through each of the 5 stations. Upon completion of all stations, students participated in a focus group to express their opinions of the educational project and complete an exit questionnaire. Students were asked to rate each of the stations on a scale of 1 to 5 , where $1=$ no educational value, and $5=$ very valuable educational experience.

RESULTS: Data from 224 students are presented in Table 1 which summarizes their opinions of the educational value of each station. Students highly rated the high-fidelity simulation experience. Descriptive comments regarding the strengths of the educational session included: high-fidelity simulation $(\mathrm{n}=52)$, hands-on experience $(\mathrm{n}=32)$, and learning atmosphere $(\mathrm{n}=20)$. Weaknesses listed included: too much time at part-task stations $(n=45)$, not enough time in HFS $(n=22)$ and need for pharmacology introduction before session $(n=17)$.

DISCUSSION: Students found both part-task and HFS sessions valuable but felt that more time was warranted for 'practicing' scenarios using HFS and less time at part-task stations. 
Table 1: Mean and SD of edhcational value of simulation stations 1"no educational value, 5 -very valuable educational experience

\begin{tabular}{|l|l|l|l|l|l|l|}
\hline & Monitors & $\begin{array}{l}\text { IV } \\
\text { catheterization }\end{array}$ & $\begin{array}{l}\text { Laerdal } \\
\text { Head }\end{array}$ & $\begin{array}{l}\text { AirSin } \\
\text { Head }\end{array}$ & HFS & $\begin{array}{l}\text { Should be } \\
\text { offered } \\
\text { next year }\end{array}$ \\
\hline N & 217 & 223 & 223 & 220 & 224 & 224 \\
\hline Mean & 3.62 & 3.87 & 4.39 & 4.24 & 4.93 & 4.94 \\
\hline SD & 0.92 & 0.98 & 0.66 & 0.71 & 0.26 & 0.26 \\
\hline
\end{tabular}

